\title{
Development of strips of ovine testes after xenografting under the skin of mice and co-transplantation of exogenous spermatogonia with grafts
}

\author{
Jose R Rodriguez-Sosa ${ }^{1}$, Robert A Foster ${ }^{2}$ and Ann Hahnel ${ }^{1}$ \\ Departments of ${ }^{1}$ Biomedical Sciences and ${ }^{2}$ Pathobiology, Ontario Veterinary College, University of Guelph, Guelph, \\ Ontario, Canada N1G 2W1 \\ Correspondence should be addressed to J R Rodriguez-Sosa who is now at Department of Comparative Biology and Experimental \\ Medicine, Faculty of Veterinary Medicine, University of Calgary, 3330 Hospital Drive NW, Calgary, Alberta, Canada T2N 4N1; \\ Email: jrrodrig@ucalgary.ca
}

\begin{abstract}
Xenografting of testicular tissue is an attractive new strategy for studying postnatal development of spermatogenesis and to preserve male genetics in large mammals. Typically, small cubes of immature testis $\left(\mathbf{1} \mathbf{~ m m}^{3}\right)$ are grafted under the dorsal skin of immune-deficient mice. We attempted to increase the total number of seminiferous tubules in each xenograft with spermatogenesis by grafting flat strips of testis $(\sim 9 \times 5 \times 1 \mathrm{~mm})$ from ram lambs in immune-deficient mice. The percentage of grafts that survived and percentage of seminiferous tubules that developed spermatogenesis were the same as those reported after xenografting small cubes of lamb testis. Partially purified sheep spermatogonia were labeled with the fluorescent dye carboxy fluorescein diacetate succinyl diester and transplanted into the seminiferous tubules of one of the donor testis just before engraftment. The temporary label in the donor cells was detected for 4 weeks after xenografting, suggesting that co-engraftment of spermatogonia with testicular tissue may be a way to rapidly determine the effect of a specific gene on spermatogenesis. Finally, Sertoli cell lesions in xenografts of lamb testes were quantified, and their number and severity were found to increase, especially after grafts had been in place for 4 weeks. Although this coincided with the development of spermatogenesis, the extent of germ cell differentiation negatively correlated with severity of the lesions.
\end{abstract}

Reproduction (2010) 139 227-235

\section{Introduction}

It is well established that pieces of testis from immature mammals that are grafted under the skin of adult immunedeficient and castrated mice can establish hormonal signaling with the mouse hypothalamo-hypophyseal axis, secrete androgen and attain spermatogenesis and production of fertilization-capable spermatozoa (Honaramooz et al. 2002, 2004, 2008, Schlatt et al. 2002). Since the publication of the first reports, xenografting of testicular tissue has emerged as an attractive technology for preserving the genetics of valuable males and to study postnatal development of spermatogenesis (Rodriguez-Sosa \& Dobrinski 2009). It is an especially economical way to study large animal spermatogenesis because multiple mice can be engrafted from a single testis, and these can be given different treatments and collected at multiple time points.

Engrafting of testicular tissue from newborns of a variety of species to immune-deficient mice has resulted in production of spermatozoa (Rodriguez-Sosa \& Dobrinski 2009), although average percentage of tubules with spermatozoa has varied with species, notably from
$<15 \%$ in grafts from calves (Oatley et al. 2004, 2005, Rathi et al. 2005, Schmidt et al. 2006a, 2006b) to 64\% in grafts from sheep (Zeng et al. 2006). The applications of xenografting of testicular tissue make it desirable that a high number of seminiferous tubules obtain full spermatogenesis. Most researchers currently graft small cubes $\left(\sim 0.5-1 \mathrm{~mm}^{3}\right)$ of tissue, and the small size of the grafts limits the number of seminiferous tubules that might have spermatogenesis for study or harvest.

Ovarian strips have been used for autologous transplantation and have resulted in temporary recovery of ovarian function in humans (Radford et al. 2001), and recovery of fertility in sheep (Gosden et al. 1994a). Xenografting of ovarian cortical strips from sheep and cats into immune-deficient mice resulted in follicular development (Gosden et al. 1994b). However, the use of similar strips in testis tissue xenografting has not been reported. In the current study we validate the use of flat strips of ram lamb testes $(\sim 9 \times 5 \times 1 \mathrm{~mm})$ for grafting in immune-deficient mice as a potential way to increase the final number of seminiferous tubules with full spermatogenesis in each xenograft. 
Secondly, we explored survival of spermatogonia transplanted into the seminiferous tubules of a ram lamb testis before slicing and producing the strips. 'Co-engraftment' of testis tissue and exogenous spermatogonia might be a fast and inexpensive way to produce transgenic sperm or to evaluate the role of specific genes after genetic modification of donor spermatogonia. We discovered that donor cells stay in the seminiferous tubules during the subsequent engraftment, and that at least some survive the critical first 2 weeks in xenografts. Finally, we quantify Sertoli cell abnormalities during development of ovine testis xenografts. Signs of Sertoli cell abnormality have not been quantified in xenografts, nor has their presence in a tubule been correlated with stage of germ cell differentiation. We find Sertoli cell lesions and spermatogenesis in the same seminiferous tubules of xenografts, but that the severity of the lesions is inversely correlated with extent of germ cell differentiation.

\section{Results}

\section{Recovery and endocrine activity of xenografts}

Of the 32 ovine testis strips grafted under the skin of RAG-1 mice (Fig. 1 and Table 1), 31 (97\%) were recovered and contained viable tissue. The average length of the four grafts recovered 16 weeks after engraftment was $2.2 \mathrm{~cm}$; $\sim 2.4$ times that of the strips used for grafting (Fig. 2A). Vesicular glands were recovered from all mice sacrificed between 4 and 16 weeks after engraftment, and all had columnar epithelium with abundant apical vesicles (Fig. 2B), indistinguishable from that of noncastrated mice (Tsuji et al. 1998).

\section{Development of xenografts}

In all four of the testes used to make testicular strips for xenografting, seminiferous tubules had an intact Sertoli cell lining with no lesions. A representative photomicrograph from a graft-donor testis is shown in Fig. 2C. Each of the four graft-donor testes had initiated the first wave of spermatogenesis: five sections from each of the four testes were analyzed and $90 \pm 6.5 \%$ of tubules contained a lumen, pachytene primary spermatocytes were the most differentiated germ cell in $69 \pm 5.0 \%$ of tubule cross-sections, spermatogonia in $30 \pm 5.5 \%$, and only $0.4 \pm 4.5 \%$ tubule cross-sections had no detectable germ cells (Fig. $3 \mathrm{~A}-\mathrm{C}$, week 0 ). There was no significant difference between the four graft donors $(P>0.05)$.

In the xenografts collected at 1 and 2 weeks after transplantation, $78 \pm 2.5$ and $70 \pm 3.2 \%$ of seminiferous tubules had a complete Sertoli cell lining respectively. The remainder contained no Sertoli cells or had a partial Sertoli cell lining (Figs 2D and 3A). However in the 12 grafts recovered after 6 weeks, $>90 \%$ of tubules had a

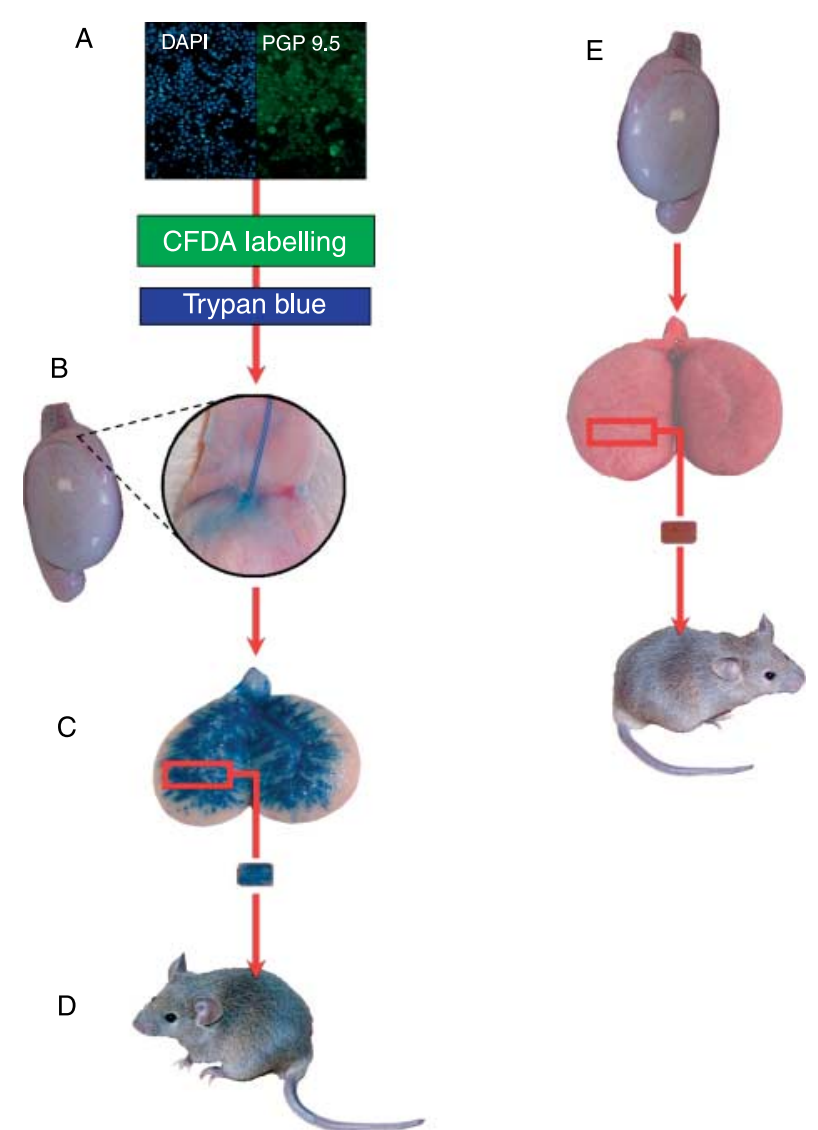

Figure 1 Experimental approach used in the current study. (A-D) Co-engraftment of donor cells (spermatogonia or somatic) with testis strips. (A) Cell fractions enriched in spermatogonia (PGP 9.5 positive cells) or somatic cells from lamb testes were labeled with CFDA and diluted in a solution containing $0.04 \%$ trypan blue.

(B) Labeled cells were transplanted ex vivo into the seminiferous tubules of lamb testes (numbers 3 and 4 respectively in Table 1) via the extratesticular rete testis. (C) Each testis was bisected, and strips were made from areas with good distribution of trypan blue. (D) The strips $(\sim 9 \times 5 \times 1 \mathrm{~mm})$ were subsequently grafted under the dorsal skin of RAG-1 mice. (E) Strips were also made from two testes that were not transplant recipients (numbers 1 and 2 in Table 1) and grafted under the dorsal skin of RAG-1 mice.

complete Sertoli cell lining $(92 \pm 2.5,99 \pm 0.9$, and $93 \pm 2.1 \%$ at 6,8 , and 16 weeks respectively, Fig. $3 \mathrm{~A}$ ). Tubules without a complete Sertoli cell lining were generally located in the center of the xenografts and always had coagulative necrosis (Fig. 2E). At 3 weeks after transplantation, some tubules with no Sertoli cells were filled with mineralized material, and at 4-16 weeks all tubules without Sertoli cells contained mineralized debris. Germ cells were present with Sertoli cells even in cross-sections of tubules with a partial Sertoli cell lining (Fig. 2F).

In the xenografts collected 1 week after surgery, the number of seminiferous tubules with complete Sertoli cell lining that contained a lumen was $4 \pm 5.1 \%$. However, the percentage increased to $\sim 45 \%$ in the 
Table 1 Transplantation design and collection time points.

Collection (no. mice/time point) ${ }^{\mathrm{a}}$

\begin{tabular}{|c|c|c|c|c|c|c|c|c|}
\hline $\begin{array}{l}\text { Mouse } \\
\text { recipients }^{b}\end{array}$ & Graft-donor testis $^{\mathrm{C}}$ & Week 1 & Week 2 & Week 3 & Week 4 & Week 6 & Week 8 & Week 16 \\
\hline $\begin{array}{l}\text { Group I } \\
\quad(n=8)\end{array}$ & $\begin{array}{l}\text { Testis } 1+2 \text { : no } \\
\quad \text { exogenous cells }\end{array}$ & 1 & & & 1 & 2 & 2 & 2 \\
\hline $\begin{array}{l}\text { Group II } \\
\quad(n=6)\end{array}$ & Testis 3: Sg recipient $^{\mathrm{d}}$ & 1 & 2 & 2 & 1 & & & \\
\hline $\begin{array}{l}\text { Group III } \\
\quad(n=2)\end{array}$ & $\begin{array}{l}\text { Testis 4: somatic cell } \\
\text { recipient }^{\mathrm{d}}\end{array}$ & 1 & & & 1 & & & \\
\hline
\end{tabular}

${ }^{a}$ At each time point, two grafts were removed from each mouse for analysis. ${ }^{\text {b}}$ Recipient mice were T- and B-cell-deficient adults (RAG- 1 null X Tie2lacZ). ${ }^{\mathrm{C}}$ Donor ram lamb testes were between 20 and $25 \mathrm{~cm}^{3}$ and were all similarly in first wave of spermatogenesis with pachytene spermatocytes as the most differentiated germ cell type. ${ }^{\mathrm{d}}$ Testes 3 and 4 were themselves recipients of either a ram lamb spermatogonial or somatic cell fraction. Donor ram lamb cells were prepared and injected into the seminiferous tubules of the graft-donor testis just prior to preparation of the recipient testis for grafting as described in Materials and Methods.

xenografts collected at 2,3 , and 4 weeks and to $88 \pm 7.5 \%$ at 6 weeks (Fig. $4 \mathrm{~A}$ and B). Similar trends were seen in tubule and lumen diameters among tubules with intact Sertoli cell lining. There was a decrease in both diameters at 1 week, but by 6 weeks tubular diameter was higher than the starting value, whereas lumen diameter was not higher until 8 weeks (Fig. 4C).

At 1 week after grafting and in tubules with a complete Sertoli cell lining, spermatogonia were detected in $69 \pm 3.9 \%$ of tubule cross-sections, and spermatocytes were absent. No germ cells were detected in $31 \pm 4.0 \%$ of tubules (Fig. 3B). However, the number of tubules with a complete Sertoli cell lining that had spermatocytes was $96 \pm 4.9$ and $100 \pm 0.2 \%$ at 6 (Fig. 3B) and 8 weeks (Figs 3B and 5C) respectively. The number of tubules with spermatocytes as the most differentiated stage decreased at 16 weeks with the appearance of postmeiotic germ cells. In the four grafts collected at 16 weeks, spermatocytes were the most differentiated germ cell in $44 \pm 5.0 \%$ of tubules, round spermatids in $13 \pm 2.1 \%$ of tubules and elongated spermatids in $16 \pm 2.5 \%$ of tubules (Figs $3 \mathrm{~B}$ and $5 \mathrm{D}$ ). Spermatozoa were present in the lumina of some tubules (Fig. 5D). Concomitant with germ cell differentiation, tubules solely with spermatogonia or Sertoli cells decreased in number.

\section{Fate of exogenous spermatogonia in xenografts}

Spermatogonial and somatic cell fractions were purified by Percoll gradients from two testes (each $45 \mathrm{~cm}^{3}$ ). Five sections from each of these testis were examined for stage of differentiation, and pachytene spermatocytes were the most advanced type of germ cell in 79.2 $\pm 4.7 \%$ of tubules. Both cell populations were labeled with carboxy fluorescein diacetate succinyl diester (CFDA), and each fraction was transplanted into the seminiferous tubules of a different ram lamb testis ex vivo. Strips from each of these testes were immediately grafted under the dorsal skin of mice as illustrated in
Fig. 1 and described in Table 1. A whole mount of a testicular strip prepared from the testis injected with CFDA-labeled spermatogonial fraction cells is shown in Fig. 6A. Most seminiferous tubules in the strip contain donor (fluorescent) cells. Paraffin sections from different depths in the strip were immunostained to detect fluorescein-labeled cells, and an example is presented in Fig. 6B. It shows that at the time of engrafting there were CFDA-positive donor cells in $\sim 22 \%$ (range $20-23 \%$ ) of cross-sections of seminiferous tubules in the testicular strips. In paraffin sections from xenografts prepared from this same testis, donor cells were detected in $3.5,2.9,1$, and $1.2 \%$ of seminiferous tubules at 1,2, 3, and 4 weeks after xenografting respectively. At 1 and 2 weeks after xenografting, fluorescein-labeled cells were detected in tubules with and without an intact Sertoli cell lining. Those in tubules with a complete Sertoli cell lining were mostly single and some had extended processes toward the basal lamina between Sertoli cells (Fig. 6C and D), while those in tubules lacking a Sertoli cell lining were among the necrotic debris (Fig. $6 \mathrm{E}$ and F). At 3 and 4 weeks after transplantation, almost all donor spermatogonia that could be detected by immunohistochemistry were in the center of tubules with necrotic debris. Xenografts from the testis transplanted with somatic cells were collected at 1 or 4 weeks, and CFDA-positive cells were detected in 4.8 and $1.6 \%$ of seminiferous tubules respectively. At both time points, the somatic cells were found in tubules with and without a complete Sertoli cell lining. No somatic fraction cells were seen with extended processes.

\section{Histopathology of xenografts}

Cross-sections of seminiferous tubules with a complete Sertoli cell lining were scored also for Sertoli cell vacuolation and flattening (Fig. 3C). Figures $2 \mathrm{C}$ and $5 \mathrm{~A}-\mathrm{D}$ show tubules with Sertoli cells considered 'normal' over the period of study (columnar and without 

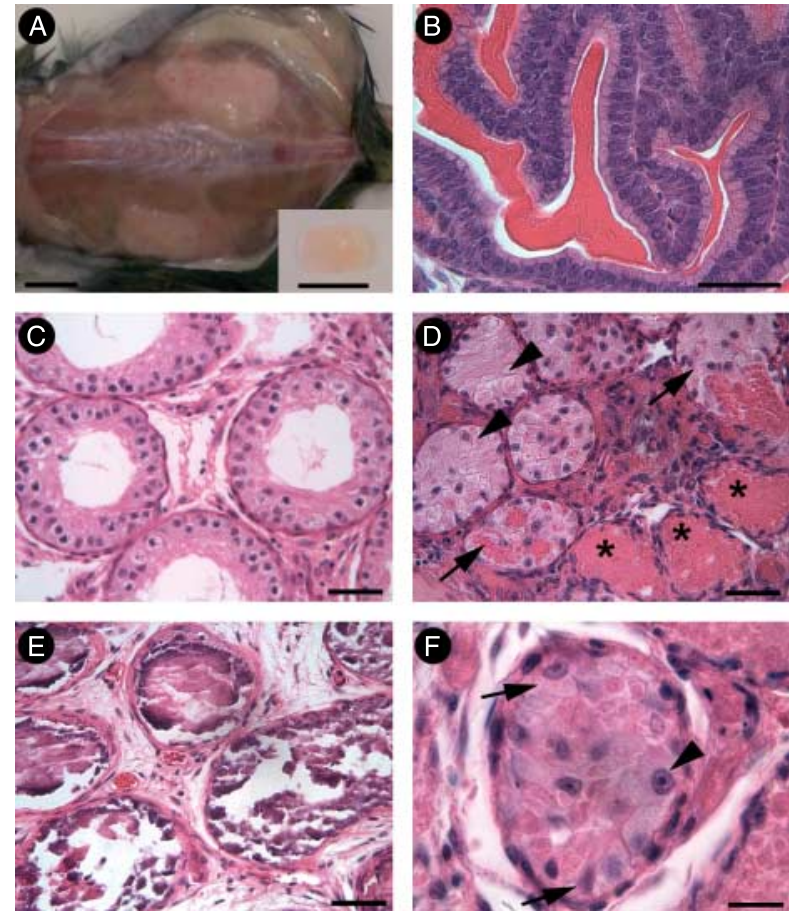

Figure 2 Gross morphology and androgenic activity of grafts (A and B), and histology of engrafted seminiferous tubules (C-F) of ovine testes in RAG-1 mice. (A) Photograph of testis grafts in situ 16 weeks after transplantation. Inset: flat strips of testes $(\sim 9 \times 5 \times 1 \mathrm{~mm})$ prior to being grafted (bars, $1 \mathrm{~cm}$ ). (B) Histology of vesicular glands of a recipient mouse killed 4 weeks after receiving a testicular xenograft.

The epithelium is columnar and there are secretory vesicles and evidence of secretion (bar, $50 \mu \mathrm{m}$ ). (C) Photomicrograph from a testis that was a graft donor. Pachytene spermatocytes are the most advanced germ cell type (bar, $50 \mu \mathrm{m}$ ). (D) Photomicrograph of a graft collected at 1 week demonstrating the three categories for integrity of the Sertoli cell epithelium: no Sertoli cells (asterisks); partial Sertoli cell lining (arrows); and complete Sertoli cell lining (arrowheads; bar, $50 \mu \mathrm{m}$ ). (E) Photomicrograph showing tubules filled with mineralized debris (bar, $50 \mu \mathrm{m}$ ). (F) Higher magnification of a seminiferous tubule with a partial Sertoli cell lining from a xenograft 1 week after transplantation. The necrotic content is surrounded by Sertoli cells (arrows) and spermatogonia (arrowhead; bar, $50 \mu \mathrm{m}$ ).

vacuoles). Figure 7A provides examples of Sertoli cell lesions (moderately vacuolated, severely vacuolated, and flat). The percentage of normal tubules decreased from $100 \%$ at engraftment to $90-95 \%$ during weeks $2-4$, but there is a further and precipitous drop from 6 to 16 weeks $(52 \pm 4.9 \%$ at 6 weeks, $30 \pm 5.0 \%$ at 8 weeks, and $5 \pm 2.5 \%$ at 16 weeks). There was also an increase in the number of Sertoli cell lesions from 2 to 16 weeks, and a notable increase in severely vacuolated Sertoli cells starting at 6 weeks.

At 16 weeks after transplantation, tubules in each of the four categories of Sertoli cell lesion were further classified by stage of germ cell differentiation. As shown in Fig. 7B and $\mathrm{C}$, the highest percentage of tubules with elongated spermatids was in the normal Sertoli cell category, and there was a decrease in the percentage of tubules with elongated spermatids as the Sertoli cell changes became more severe. No 'flat' tubules had elongated spermatids, and there was an increase in tubules without germ cells in this category. However, there were differentiating germ cells (spermatocytes, round spermatids) in tubules with all types of Sertoli cell lesions.

\section{Discussion}

Maximizing the number of seminiferous tubules with complete spermatogenesis is important for many of the applications proposed for testicular xenografting. The flat strips of testis from prepubertal ram lambs in this study survived engraftment and developed similarly to that reported for $1 \mathrm{~mm}^{3}$ pieces from newborn lambs (Zeng et al. 2006, Arregui et al. 2008). Both in this study and that of Arregui et al. (2008), grafts were collected up to 16 weeks after transplantation, and percentage of grafts that were recovered was 97 and $96 \%$ respectively. In this study, elongated spermatids were not detected at
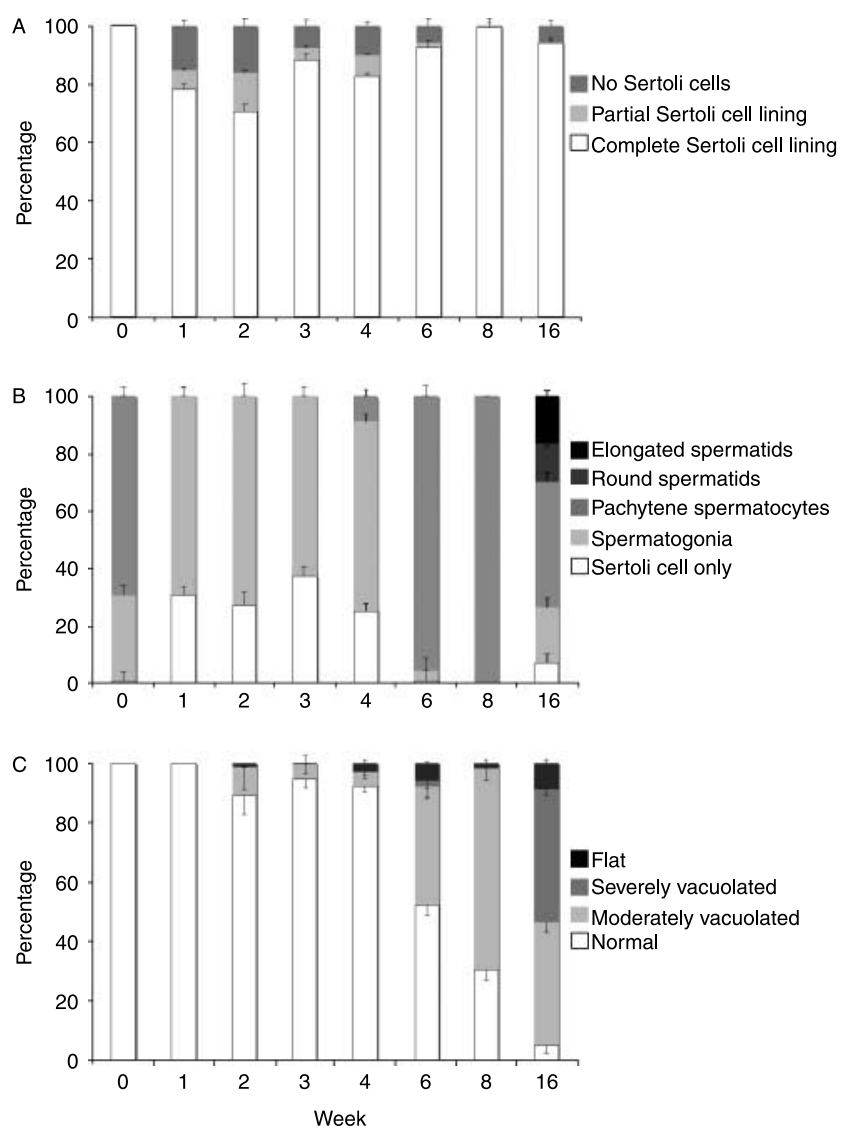

Figure 3 Observations of mean percentage of seminiferous tubules with Sertoli cell lining, stage of spermatogenesis and Sertoli cell vacuolation in ovine testicular xenografts in RAG-1 mice. (A) Completeness of Sertoli cell lining in cross-sections of seminiferous tubules. Categories are as illustrated in Fig. 2D. (B) Cross-sections of tubules with complete Sertoli cell lining were subsequently scored for the most advanced type of germ cell present and (C) Sertoli cell lesions. Error bars represent S.E.M. 

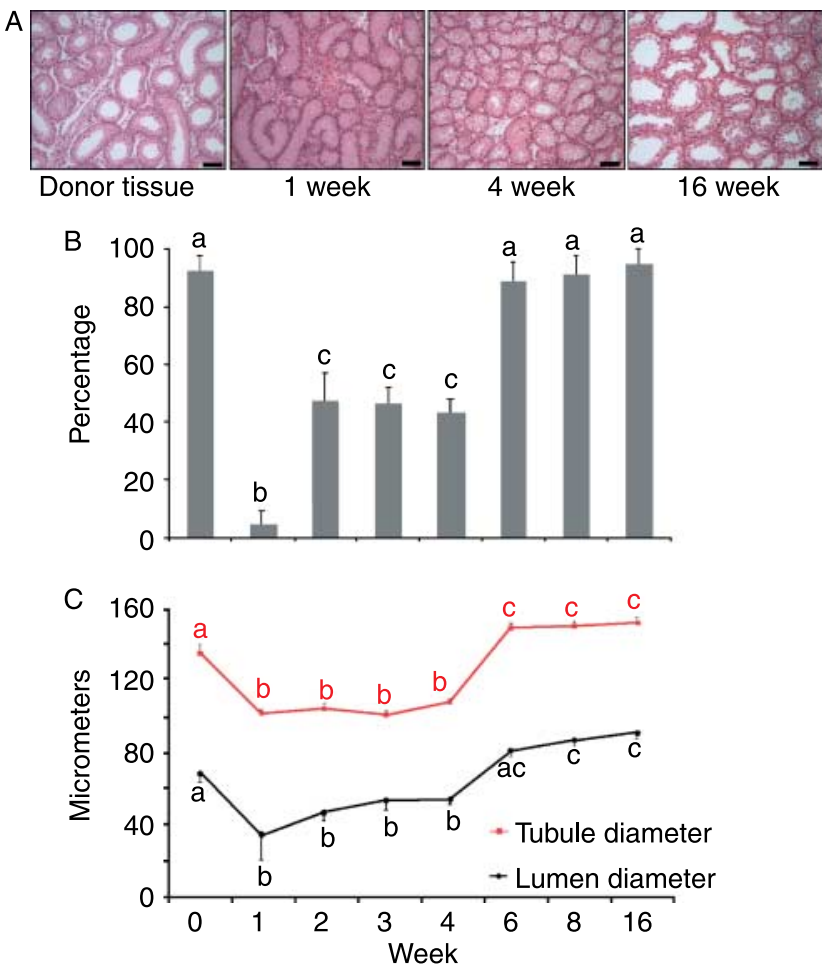

Figure 4 Percentage of tubules with a lumen, tubule, and lumen diameters in donor tissue and xenografts. (A) Photomicrographs of donor tissue and xenografts collected at different time points showing loss and reappearance of tubule lumina (bars, $100 \mu \mathrm{m}$ ). (B) Percentage of tubule cross-sections with lumina at various times after engraftment. Different letters above bars represent statistical difference between time points $(P<0.05)$. (C) Seminiferous tubule and lumen diameters at various times after engraftment. Different letters above points represent statistical difference between time points $(P<0.05)$. Error bars represent S.E.M.

8 weeks, but were detected at 16 weeks in $16 \%$ of tubules, while in the Arregui et al. (2008) study they were not detected at 8 weeks and were present at 16 weeks in $19 \%$ of tubules. Although small cube xenografts were not included in this study, the size of our strips $\left(\sim 45 \mathrm{~mm}^{3}\right)$ at xenografting is much bigger than the cubic pieces $\left(\sim 1 \mathrm{~mm}^{3}\right)$ used by Arregui et al. (2008), and thus it is reasonable to expect that there will be more seminiferous tubules with complete spermatogenesis in each of the strip xenografts than in each small cube of tissue.

Our study is the first one to quantify seminiferous tubule lesions after xenografting. As expected, tubules degenerated after ectopic xenografting. Transplantation ischemia causes tissue damage and loss of cells (Jasson \& Carlsson 2002, Israely et al. 2004). In this study, no more than $30 \%$ of seminiferous tubules were lost during the ischemic period (first 2 weeks), and damage was seen as loss of Sertoli cells and differentiated germ cells, coagulative necrosis, and loss of tubule lumina. The highest percentage of tubules with no Sertoli cells or with incomplete Sertoli cell linings was during the first
2 weeks, and this is in agreement with the time required for revascularization of ovarian and pancreatic tissues after transplantation (Jasson \& Carlsson 2002, Israely et al. 2004). Loss of meiotic and postmeiotic germ cells and loss of lumina have been reported by others (Rathi et al. 2005, 2006). It was hypothesized that meiotic germ cells are more dependent on aerobic respiration (Rathi et al. 2005, Kim et al. 2007, Kumar et al. 2007), and that loss of perfusion would also result in a lack of gonadotropin support. Coagulative necrosis predominated during the first 2 weeks, and this was gradually replaced by mineralization of the lumen contents. Mineralization is a result of continuous deposition of calcium and other ions within the cytoplasm of dead cells (Kumar et al. 2007).

By 4 weeks after xenografting, androgen production by the testicular graft was sufficient to support normal seminal vesicles and presumably Sertoli cell function. Vesicular glands are highly androgen-dependent and castration in mice results in flattening of the columnar epithelium and absence of secretory vesicles by $\sim 2$ weeks after surgery (Tsuji et al. 1998). A histological appearance comparable to that of noncastrated mice was therefore considered indicative of production of bioactive androgens by xenografts. Others detected a significant increase in circulating testosterone at 4 weeks after transplantation of bovine, mouse, and primate testicular tissue (Schlatt et al. 2003, Oatley et al. 2004). The increase in percentage of tubules lined by Sertoli cells after 2 weeks and the decrease in the percentage of tubules without germ cells after 3 weeks suggest regeneration of the seminiferous epithelium through the proliferation of viable cells in adjacent areas. However, the same changes would result from loss of the tubules
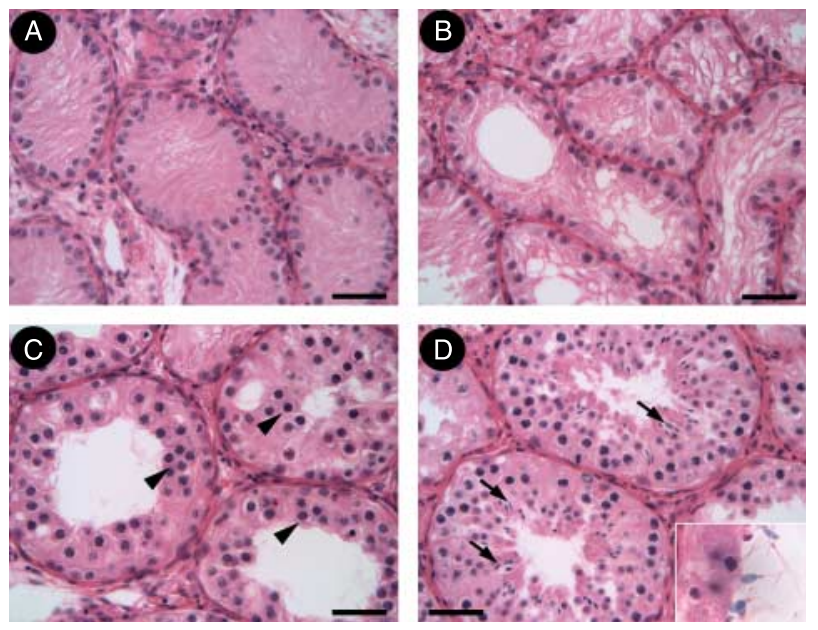

Figure 5 Development and spermatogenesis in xenografts. Representative micrographs of tubules with intact Sertoli cell lining from xenografts collected at 2 (A), 4 (B), 8 (C), and 16 (D) weeks. Notice the presence of spermatocytes in $\mathrm{C}$ (arrowheads) and elongated spermatids in D (arrows). Inset in D: higher magnification $(100 \times)$ from a 16-week xenograft with spermatozoa (Bars, $50 \mu \mathrm{m}$ ). 

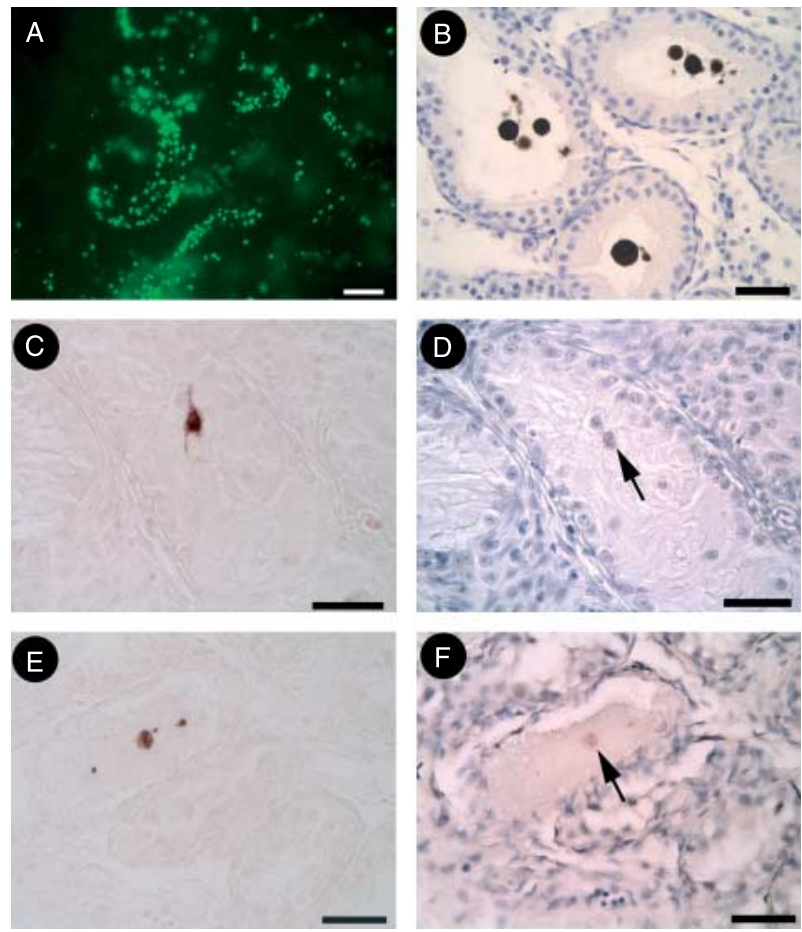

Figure 6 CFDA-labeled donor spermatogonia in seminiferous tubules of testicular xenografts. Donor cells were detected directly by epifluorescence (A) or by immunostaining for fluorescein (B-F). (A) Fluorescence photomicrograph of a whole mount of a testicular strip before engraftment (bar, $150 \mu \mathrm{m}$ ). (B) Photomicrograph from a paraffin section of the testicular strip shown in (A) after immunostaining for fluorescein $(\mathrm{bar}=50 \mu \mathrm{m})$. (C) CFDA-positive cell from the spermatogonial fraction in a seminiferous tubule with a complete Sertoli cell lining in a section from a graft that was collected 1 week after transplantation. Notice the cytoplasmic processes extending between Sertoli cells (bar, $50 \mu \mathrm{m}$ ). (D) Counterstaining of the same section shown in (C). CFDA-positive cell in (C) is pointed out by arrow (bar, $50 \mu \mathrm{m}$ ). (E) Positive cell from the spermatogonial fraction 4 weeks after engraftment in a tubule with an incomplete Sertoli lining and coagulative necrosis (bar, $50 \mu \mathrm{m}$ ). (F) Counterstaining of the same section shown in (E). CFDA-positive cell in (E) is pointed out by arrow (bar, $50 \mu \mathrm{m}$ ).

without Sertoli cells and germ cells. Deanesly (1954) suggested that damaged tissue in ovarian grafts was removed rather than replaced.

We envision co-engraftment of exogenous spermatogonial stem cells with testicular xenografts being used to study the effect of altered gene expression on testis function in large mammals. However, success will depend on exogenous spermatogonia surviving the period of ischemia in the xenograft. In this study, cells from a fraction enriched in ram spermatogonia survived transplantation into a ram lamb testis and subsequent engraftment of strips from this testis in immune-deficient mice. At 2 weeks after grafting, $\sim 1 / 6$ of these cells could be detected. Only $\sim 1 / 18$ of these cells could be detected at 4 weeks after engraftment, but the cell tracking label (CFDA) used to detect donor cells is a temporary label that will be lost by cell division and through protein turnover (Parish 1999). Therefore, we expected to lose the ability to visualize donor spermatogonia after 2 weeks, and we hypothesized that this would be due to the proliferation of the spermatogonia rather than death. Therefore, the persistence of small numbers of cells from both the spermatogonial and somatic fractions at 4 weeks was surprising. Cells that are not incorporated into a functional epithelium or are in necrotic areas may retain the label because they are not dividing. Donor spermatogonia that have been transduced to permanently express a gene such as GFP are needed in future studies to determine the long-term fate of exogenous spermatogonia in xenografts and to prove a contribution to xenograft spermatogenesis.

Another surprising finding was that the number of lesions in Sertoli cells (flattening and vacuoles) rose markedly after 4 weeks, even as the percentage of
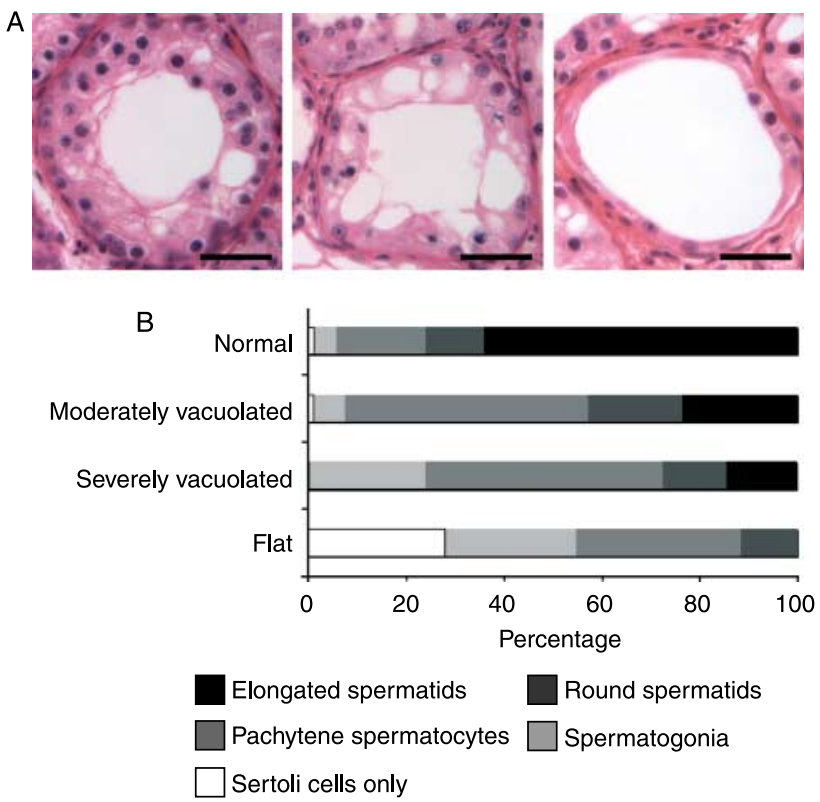

C Sertoli
cells only Spermatogonia Spermatocytes $\begin{gathered}\text { Round } \\ \text { spermatids }\end{gathered}$ spermatids

$\begin{array}{llllll}\text { Normal } & \text { a } & \text { a } & \text { a } & \text { a } & \text { a } \\ \begin{array}{l}\text { Moderately } \\ \text { vacuolated }\end{array} & \text { a } & \text { a } & \text { b } & \text { a } & \text { b } \\ \begin{array}{l}\text { Severely } \\ \text { vacuolated }\end{array} & \text { a } & \text { b } & \text { b } & \text { a } & \text { c } \\ \text { Flat } & \text { b } & \text { b } & \text { c } & \text { a } & \text { d }\end{array}$

Figure 7 Sertoli cell lesions and spermatogenesis in ovine xenografts. (A) Photomicrographs with examples of the Sertoli cell lesions: moderately vacuolated (left); severely vacuolated; (center); and flat (right; bars, $50 \mu \mathrm{m}$ ). Examples of tubules that were classified as normal are shown in Figs 2C and 5A-D. (B) Quantification of spermatogenesis in cross-sections of seminiferous tubules with each category of Sertoli cell lesion at 16 weeks after engraftment. (C) Statistical significance for differences in percentages of same cell type (areas of bar with same color in (B) between each category of Sertoli cell lesion. Different letters within a column represent statistical difference $(P<0.05)$. 
tubules with spermatogenesis increased. There were differentiated germ cells in tubules with lesions, although the more severe the lesion in a tubule, the less differentiated the germ cells. Sertoli cell flattening could result from there being no exit for fluid generated by the seminiferous epithelium (Schlatt et al. 2003). Efferent duct ligation and 'knock out' of the estrogen receptor result in tubule dilation and presence of vacuoles (Wang et al. 1985, Eddy et al. 1996). However, fluid accumulation may not be the only cause of Sertoli cell lesions in xenografts. A wide range of testicular insults are associated with vacuoles in the seminiferous epithelium, but those seen in cryptorchid testes as a result of heat stress may be particularly relevant to vacuoles in testicular grafts under the dorsal skin of mice (Yin et al. 1997, Kerr 1998). Testicular temperature in sheep is reported to be $34.1^{\circ} \mathrm{C}$ (Waites \& Moule 1961), while subcutaneous temperature of mice with hair is $\sim 37^{\circ} \mathrm{C}$ (Carmo et al. 2003). Most testicular xenografts in mice have been to a subcutaneous site (Rodriguez-Sosa \& Dobrinski 2009), although an early study by Turner (1938) indicated that the highest rates of homologous graft survival and spermatogenesis in rats were obtained from grafts placed into the anterior chamber of the eye. He attributed this success to a combination of lower temperature (similar to the scrotum) and the nutritive environment provided by the fluid of the eye. However, the amount of tissue than can be placed into the mouse eye is limited and transplantation into this site is logistically difficult.

In conclusion, the results of our study represent a substantial contribution to the field by demonstrating that it is feasible to xenograft testis strips in immunedeficient mice without decreasing tubule survival or differentiation in comparison to previous reports of small cube xenografts. Moreover, our novel co-engraftment scheme seems promising in light of survival of donor cells through the ischemic period after xenografting the recipient testis. This survival suggests that donor spermatogonia might contribute to spermatogenesis in xenografts; however, permanently labeled cells are needed to prove this contribution. Finally, we used quantitative analysis to demonstrate that although germ cells differentiate in the presence of Sertoli cell lesions, the amount of differentiation inversely correlates with the severity of the lesion.

\section{Materials and Methods}

\section{Donor testes and recipient mice}

Sheep testes of unknown age, breed, and hormonal status were obtained from a local abattoir and transported to the laboratory on ice. Testicular tissue was prepared for engrafting from four testes that were between 20 and $25 \mathrm{~cm}^{3}$. Each of these testes was in the first wave of spermatogenesis with pachytene spermatocytes as the most differentiated cell type (see Results).
The donor cells that were transplanted into two of these four testes were purified from two $45 \mathrm{~cm}^{3}$ testes obtained earlier from the same abattoir, but these testes were also in the first wave of spermatogenesis with pachytene spermatocytes as the most advanced type of germ cell (see Results). Testicular volume was calculated using the formula of Steger \& Wrobel (1994). The xenograft recipients were adult T- and B-celldeficient RAG-1 null mice (B6.12957-Ragltm/Mom) that had been crossed to Tie2lacZ mice (FVB/N-TgN(TIE2-lacZ)182Sato; Fathers et al. 2005) to incorporate the lacZ transgene, and were kindly provided by Dr Brenda Coomber.

\section{Experimental design}

Of the four ram lamb testes used for xenografting, one was injected just before engraftment with a cell fraction enriched in spermatogonia that were labeled with CFDA. Another was injected just before engraftment with a cell fraction enriched in somatic cells labeled with CFDA, and two testes did not receive exogenous cells prior to engraftment (Fig. 1 and Table 1). Tissue strips of $\sim 9 \times 5 \times 1 \mathrm{~mm}$ were prepared from each of these four testes and were grafted under the dorsal skin of castrated RAG-1 mice. In total there were 16 mouse recipients, and each received two grafts from the same donor testis. Mice were sacrificed and grafts were collected at 1-16 weeks later. All animal procedures were approved by the Animal Care Committee of the University of Guelph.

\section{Spermatogonial transplantation and preparation of testicular grafts}

\section{Spermatogonial transplantation}

Spermatogonial and somatic cell fractions were purified from two $45 \mathrm{~cm}^{3}$ testes (see above) by a two step enzymatic procedure and Percoll gradients as previously described (Rodriguez-Sosa et al. 2006). In Rodriguez-Sosa et al. (2006), we found that the spermatogonial fraction (Fraction A) contains on average 65\% UCHL1 (PGP 9.5) positive spermatogonia $(65.3 \pm 3.2 \%)$, and the 'somatic' fraction (Fraction B) contains $\sim 80 \%$ vimentin and smooth muscle actin positive, peritubular myoid cells $(80.8 \pm 3.2 \%)$. Cells from each fraction were frozen according to Izadyar et al. (2002). On the day of xenografting, these cells were thawed at $37^{\circ} \mathrm{C}$ for $1-2 \mathrm{~min}$ and labeled with the cell tracking dye CFDA (Molecular Probes, Eugene, OR, USA) as previously described (Rodriguez-Sosa et al. 2006). A total of $150 \times 10^{6}$ cells of each type (spermatogonial or somatic) were suspended in $3 \mathrm{ml}$ of $0.04 \%$ trypan blue in sterile PBS. Also on the day of xenografting, two $20-25 \mathrm{~cm}^{3}$ ram lamb testes from the abattoir (see above) were selected to be the recipients of purified spermatogonial or somatic cell fractions. Cells in trypan blue solution were injected into the seminiferous tubules of each of these two testes ex vivo by cannulation of the rete testis after blunt dissection of the head of the epididymis (Rodriguez-Sosa et al. 2006). Each testis was bisected, and the strips for grafting were immediately produced from areas with good dye distribution in seminiferous tubules (see Rodriguez-Sosa et al. 2006 for examples) and grafted into immune-deficient mice as described below. A few of these 
strips were mounted on a slide, and CFDA-labeled donor cells were directly visualized using epifluorescence and an FITC filter set. The strips examined by epifluorescence were then processed for immunohistochemistry as describe below.

\section{Testicular graft preparation}

Flat strips of testis $(\sim 9 \times 5 \times 1 \mathrm{~mm})$ were produced from each of the testes injected with partially purified spermatogonia or somatic cells and from two un-injected testes. Each testis was bisected, and the slices were produced by cutting perpendicular to the rete testis with a pair of microtome blades separated by a spacer. The strips were maintained in ice-cold Eagle's modified essential medium (Sigma) until the moment of grafting later that day.

\section{Surgical procedure}

For castration and graft surgeries, recipient RAG-1 null mice were anesthetized by i.p. administration of avertin $(0.02 \mathrm{ml} / \mathrm{g})$. Recipient mice were castrated 1 week prior to the graft surgery through a ventral mid-line incision as previously described by Schlatt et al. (2002). For the graft surgery, their backs were shaved and aseptically prepared. A $1 \mathrm{~cm}$ incision was made in the skin at each side of the dorsal mid-line, and the subcutaneous tissue was dissected to create a space. A strip of testis was placed in this space, taking special care to keep the strip flat. Incisions were closed with Michel suture clips (Fine Science Tools, North Vancouver, British Columbia, Canada).

\section{Histological evaluation of tissues}

Pieces of each of the donor testes, grafts, and vesicular glands were fixed overnight at $4{ }^{\circ} \mathrm{C}$ in modified Davidson's fluid (Latendresse et al. 2002). Fixed tissue was embedded in paraffin, sectioned at $5 \mu \mathrm{m}$ and stained with hematoxylin and eosin using standard procedures. A total of five sections per graft were analyzed, each separated by at least $50 \mu \mathrm{m}$.

All tubules in each of the five paraffin sections from a graft were first categorized on the basis of the completeness of the Sertoli cell lining. The categories were a) no Sertoli cells; b) partial Sertoli cell lining; and c) complete Sertoli cell lining. At least 75 cross-sections with a complete lining were further categorized according to the most advanced stage of germ cell present and the presence of Sertoli cell lesions. There were 75 cross-sections with a complete lining in five sections from the smallest graft. In larger grafts the same number of tubules was scored by selecting those that lay along a longitudinal or transverse line through each of the sections. Germ cell categories were as follows: a) none; b) spermatogonia (only) and spermatogenesis to c) pachytene spermatocytes; d) round spermatids; and e) elongated spermatids. Categories of lesions to Sertoli cells were as follows: a) normal (none); b) moderately vacuolated; c) severely vacuolated; and d) flat. Finally, for the grafts collected at 16 weeks, tubules in each of the category of lesions of Sertoli cells were also categorized by most advanced stage of germ cell present as described above.

All tubules with complete Sertoli cell lining in five sections were also scored for presence of lumen. Tubule diameter was measured in 50 tubule cross-sections, and lumen was also measured in those cross-sections that contained lumen. The number of tubules was determined by the number available in five sections from the smallest graft, and the 50 tubules were selected by proximity to a longitudinal or transverse axis as described above in larger grafts. Measurements were performed on digital micrographs ( $40 \times$ magnification) using Optimas 6.2 imaging software (Media Cybernetics, Silver Spring, MD, USA).

\section{Immunohistochemistry}

Donor cells were labeled with CFDA and were detected in paraffin sections by indirect immunohistochemistry as follows. Sections were processed through xylene, rehydrated, exposed to $3 \% \mathrm{H}_{2} \mathrm{O}_{2}$ in distilled water for $15 \mathrm{~min}$, washed in PBS for $5 \mathrm{~min}$, and nonspecific binding was blocked in 5\% goat serum (Vector Laboratories, Burlington, Ontario, Canada) in PBS for $30 \mathrm{~min}$ at room temperature. Tissue sections were subsequently immersed in mouse anti-FITC (Sigma) at 1:400 dilution in PBS containing $2.5 \%$ goat serum for $1 \mathrm{~h}$ at room temperature. After washing three times in PBS for 5 min each, the tissue sections were placed in biotinylated goat anti-mouse $\operatorname{lgG}(2.5 \mu \mathrm{g} / \mathrm{ml})$ for $30 \mathrm{~min}$ at room temperature and washed in PBS as above. Sections were then covered with avidin/peroxidase for $30 \mathrm{~min}$ (R.T.U. Vectastain Elite ABC Reagent), washed with PBS as above and placed in the chromogen NovaRed (all of above from Vector Laboratories) according to the manufacturer's instructions. Sections were then dehydrated through ethanol and xylene, and finally mounted in Permount (Fisher Scientific, Ottawa, Ontario, Canada). Once cells were identified and counted, coverslips were removed from slides by immersion in xylene which also removed chromogen precipitate. Sections were rehydrated and counterstained with Mayer's hematoxilin (1:1 in distilled water, Sigma) for $45 \mathrm{~s}$. Sections were finally dehydrated and mounted in Permount as described above.

\section{Statistical analysis}

Analysis of differences within categories described above was performed with ANOVA and Tukey test, and the General Linear Model (GLM) procedure of Statistical Analysis Systems (SAS, version 9.1.2, SAS Inc., Cary, NC, USA). Comparison of lesions in Sertoli cells and the most advanced type of germ cell present were performed using the $\chi^{2}$-test of the Frequency (FREQ) procedure in the same statistical program. A probability value of $P<0.05$ was considered significant in each test.

\section{Declaration of interest}

The authors declare that there is no conflict of interest that could be perceived as prejudicing the impartiality of the research reported.

\section{Funding}

This work was supported by the Ontario Ministry of Agriculture and Food and Rural Affairs (grant number 026061), the Natural 
Sciences and Engineering Research Council (grant number 047-62), and the Gartshore Memorial Sheep Research Fund (no specific number).

\section{Acknowledgements}

The authors thank Dr Anne Croy and Dr Brenda Coomber for providing mice for this and preliminary studies. We also acknowledge the help of the Animal Isolation Facility staff of the Ontario Veterinary College and the kind gift of testes by Millgrove Packers Ltd.

\section{References}

Arregui L, Rathi R, Megee SO, Honaramooz A, Gomendio M, Roldan ER \& Dobrinski I 2008 Xenografting of sheep testis tissue and isolated cells as a model for preservation of genetic material from endangered ungulates. Reproduction 136 85-93.

Carmo H, Remiao F, Carvalho F, Fernandes E, de Boer D, dos Reys LA \& de Lourdes Bastos M 2003 4-Methylthioamphetamine-induced hyperthermia in mice: influence of serotonergic and catecholaminergic pathways. Toxicology and Applied Pharmacology 190 262-271.

Deanesly R 1954 Spermatogenesis and endocrine activity in grafts of frozen and thawed rat testis. Journal of Endocrinology 11 201-2006.

Eddy EM, Washburn TF, Bunch DO, Goulding EH, Gladen BC, Lubahn DB \& Korach KS 1996 Targeted disruption of the estrogen receptor gene in male mice causes alteration of spermatogenesis and infertility. Endocrinology 137 4796-4805.

Fathers KE, Stone CM, Minhas K, Marriott JJ, Greenwood JD, Dumont DJ \& Coomber BL 2005 Heterogeneity of Tie2 expression in tumor microcirculation: influence of cancer type, implantation site, and response to therapy. American Journal of Pathology 167 1753-1762.

Gosden RG, Baird DT, Wader JC \& Webb R 1994a Restoration of fertility in oophorectomised sheep by ovarian autografts stored at $-196^{\circ} \mathrm{C}$. Human Reproduction 9 597-603.

Gosden RG, Boulton M, Grant K \& Webb R 1994b Follicular development from ovarian xenografts in SCID mice. Journal of Reproduction and Fertility 101 619-623.

Honaramooz A, Snedaker A, Bioani M, Schöler H, Dobrinski I \& Schlatt S 2002 Sperm from neonatal testes grafted in mice. Nature 418 778-781.

Honaramooz A, Li M, Penedo CT, Meyers S \& Dobrinski I 2004 Accelerated maturation of primate testis by xenografting into mice. Biology of Reproduction 70 1500-1503.

Honaramooz A, Cui X, Kim N \& Dobrinski I 2008 Porcine embryos produced after intracytoplasmic sperm injection using xenogeneic pig sperm from neonatal testis tissue grafted in mice. Reproduction, Fertility, and Development 20 802-807.

Israely T, Dafni H, Nevo N, Tsafriri A \& Neeman M 2004 Angiogenesis in ectopic ovarian xenotransplantation: mutiparameter characterization of the neovasculature by dynamic contrast-enhanced MRI. Magnetic Resonance in Medicine 52 741-750.

Izadyar F, Matthijs-Rijsenbilt JJ, den Ouden K, Creemers LB, Woelders H \& de Rooij DG 2002 Development of a cryopreservation protocol for type A spermatogonia. Journal of Andrology 23 537-545.

Jasson L \& Carlsson PO 2002 Graft vascular function after transplantation of pancreatic islets. Diabetologia 45 749-763.

Kerr JB 1998 Temperature, effects on testicular function. In Encyclopedia of Reproduction, vol 4, pp 725-734. Eds E Knobil \& JD Neill. San Diego: Academic Press.

Kim Y, Selvaraj V, Pukazhenthi B \& Travis AJ 2007 Effect of donor age on success of spermatogenesis in feline testis xenografts. Reproduction, Fertility, and Development 19 869-876.

Kumar V, Abbas AK, Fausto N \& Mitchell RN 2007 Cell injury, cell death, and adaptations. In Robins Basic Pathology, edn 8, pp 1-30. Eds V Kumar, AK Abbas, N Fausto \& RN Mitchell. Philadelphia: Saunders Elsevier.
Latendresse JR, Warbrittion AR, Jonassen H \& Creasy DM 2002 Fixation of testes and eyes using a modified Davidson's fluid: comparison with Bouin's fluid and conventional Davidson's fluid. Toxicologic Pathology 30 524-533.

Oatley JM, de Avila DM, Reeves JJ \& McLean DJ 2004 Spermatogenesis and germ cell transgene expression in xenografted bovine testicular tissue. Biology of Reproduction 71 494-501.

Oatley JM, Reeves JJ \& McLean DJ 2005 Establishment of spermatogenesis in neonatal bovine testicular tissue following ectopic xenografting varies with donor age. Biology of Reproduction 72 358-364.

Parish CR 1999 Fluorescent dyes for lymphocyte migration and proliferation studies. Immunology and Cell Biology 77 499-508.

Radford JA, Lieberman BA, Brison DR, Smith AR, Critchlow JD, Russell SA, Watson AJ, Clayton JA, Harris M, Gosden RG et al. 2001 Orthotopic reimplantation of cryopreserved ovarian cortical strips after high-dose chemotherapy for Hodgkin's lymphoma. Lancet 357 1172-1175.

Rathi R, Honaramooz A, Zeng W, Schlatt S \& Dobrinski I 2005 Germ cell fate and seminiferous tubule development in bovine testis xenografts. Reproduction 130 923-929.

Rathi R, Honaramooz A, Zeng W, Turner R \& Dobrinski I 2006 Germ cell development in equine testis tissue xenografted into mice. Reproduction 131 1091-1098.

Rodriguez-Sosa JR \& Dobrinski I 2009 Recent developments in testis tissue xenograting. Reproduction 138 187-194.

Rodriguez-Sosa JR, Dobson H \& Hahnel A 2006 Isolation and transplantation of spermatogonia in sheep. Theriogenology 66 2091-2103.

Schlatt S, Kim SS \& Gosden R 2002 Spermatogenesis and steroidogenesis in mouse, hamster and monkey testicular tissue after cryopreservation and heterotopic grafting to castrated host. Reproduction 124 339-346.

Schlatt S, Honaramooz A, Bioani M, Schöler RH \& Dobrinski I 2003 Progeny from sperm obtained after ectopic grafting of neonatal mouse testes. Biology of Reproduction 68 2331-2335.

Schmidt JA, de Avila JM \& McLean DJ 2006a Grafting period and donor age affect the potential for spermatogenesis in bovine ectopic testis xenografts. Biology of Reproduction 75 160-166.

Schmidt JA, de Avila JM \& McLean DJ 2006b Effect of vascular endothelial growth factor and testis tissue culture on spermatogenesis in bovine ectopic testis tissue xenografts. Biology of Reproduction 75 167-175.

Steger K \& Wrobel K-H 1994 Immunohistochemical demonstration of cytoskeletal proteins in the ovine testis during postnatal development. Anatomy and Embryology 189 521-530.

Tsuji M, Terada N, Sugihara A, Tsujimura T, Donjacour AA \& Cunha GR 1998 Later onset of apoptosis in the bulbourethral glands after castration compared to that in the seminal vesicles. Journal of Steroid Biochemistry and Molecular Biology 67 113-118.

Turner CD 1938 Intra-ocular homotransplantation of prepuberal testes in the rat. American Journal of Anatomy 63 101-159.

Waites GMH \& Moule GR 1961 Relation of vascular heat exchange to temperature regulation in the testis of the ram. Journal of Reproduction and Fertility 2 213-224.

Wang JM, Gu CH, Tao L \& Wu XL 1985 Effect of surgery and efferent duct ligation on testicular blood flow and testicular steroidogenesis in the rat. Journal of Reproduction and Fertility 73 191-196.

Yin Y, Hawkins KL, Dewolf WC \& Morgentaler A 1997 Heat stress causes testicular germ cell apoptosis in adult mice. Journal of Andrology $\mathbf{1 8}$ 159-165.

Zeng W, Avelar GF, Rathi R, Franca LR \& Dobrinski I 2006 The length of the spermatogenic cycle is conserved in porcine and ovine testis xenografts. Journal of Andrology 27 527-533.

Received 30 April 2009

First decision 27 May 2009

Revised manuscript received 14 September 2009

Accepted 22 September 2009 